
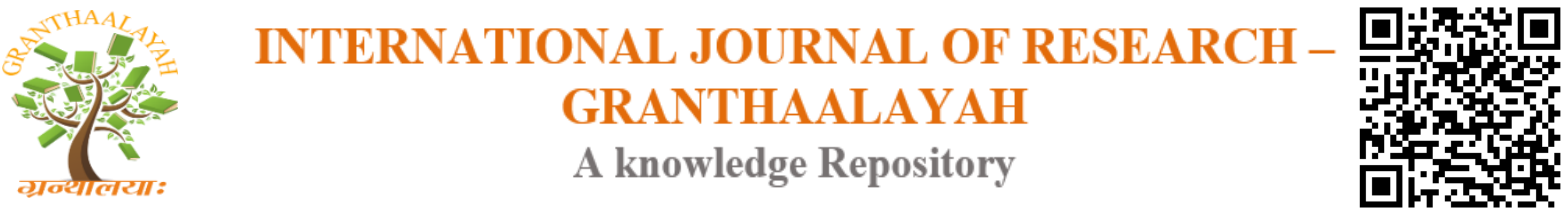

Science

\title{
WIDE-RANGING VICINITY ALGORITHM FOR SOLVING OPTIMAL REACTIVE POWER PROBLEM
}

\author{
Dr.K.Lenin *1 \\ ${ }^{* 1}$ Professor, Department of EEE Prasad V.Potluri Siddhartha Institute of Technology, Kanuru, \\ Vijayawada, Andhra Pradesh -520007, India
}

\begin{abstract}
In this paper, Wide-ranging vicinity Algorithm (WVA) is proposed to solve optimal reactive power problem. Wide-ranging vicinity Algorithm equally improves the local \& global search. From the global search space a set of arbitrary solutions are primarily generated and then the most excellent solution will give the optimal value. After that, the algorithm will iterate, \& there will be two sets of generated solutions in iteration's, one from the global search space, the other from the set of solutions \& it will be produced from the vicinity of the most excellent solution. The proposed Wide-ranging vicinity Algorithm (WVA) has been tested on standard IEEE 118 \& practical 191 bus test systems and simulation results show clearly the superior performance of the proposed Wide-ranging vicinity Algorithm (WVA) in reducing the real power loss \& voltage profiles are within the limits.
\end{abstract}

Keywords: Ranging Vicinity Algorithm; Local \& Global Search; Optimal Reactive Power; Transmission Loss.

Cite This Article: Dr.K.Lenin. (2017). "WIDE-RANGING VICINITY ALGORITHM FOR SOLVING OPTIMAL REACTIVE POWER PROBLEM." International Journal of Research Granthaalayah, 5(10), 361-368. https://doi.org/10.29121/granthaalayah.v5.i10.2017.2314.

\section{Introduction}

The main objective of optimal reactive power problem is to minimize the real power loss and bus voltage deviation. Various numerical methods like the gradient method [1-2], Newton method [3] and linear programming [4-7] have been adopted to solve the optimal reactive power dispatch problem. Both the gradient and Newton methods have the complexity in managing inequality constraints. If linear programming is applied then the input- output function has to be uttered as a set of linear functions which mostly lead to loss of accuracy. The problem of voltage stability and collapse play a major role in power system planning and operation [8]. Evolutionary algorithms such as genetic algorithm have been already proposed to solve the reactive power flow problem [9-11]. Evolutionary algorithm is a heuristic approach used for minimization problems by utilizing nonlinear and non-differentiable continuous space functions. In [12], Hybrid differential evolution algorithm is proposed to improve the voltage stability index. In [13] 
Biogeography Based algorithm is projected to solve the reactive power dispatch problem. In [14], a fuzzy based method is used to solve the optimal reactive power scheduling method. In [15], an improved evolutionary programming is used to solve the optimal reactive power dispatch problem. In [16], the optimal reactive power flow problem is solved by integrating a genetic algorithm with a nonlinear interior point method. In [17], a pattern algorithm is used to solve ac-dc optimal reactive power flow model with the generator capability limits. In [18], F. Capitanescu proposes a two-step approach to evaluate Reactive power reserves with respect to operating constraints and voltage stability. In [19], a programming based approaches used to solve the optimal reactive power dispatch problem. In [20], A. Kargarian et al present a probabilistic algorithm for optimal reactive power provision in hybrid electricity markets with uncertain loads. In this paper, Wide-ranging vicinity Algorithm (WVA) is proposed to solve optimal reactive power problem. Wide-ranging vicinity Algorithm equally improves the local \& global search. From the global search space a set of arbitrary solutions are primarily generated and then the most excellent solution will give the optimal value. After that, the algorithm will iterate, \& there will be two sets of generated solutions in iteration's, one from the global search space, the other from the set of solutions \& it will be produced from the vicinity of the most excellent solution. The proposed Wide-ranging vicinity Algorithm (WVA) has been tested on standard IEEE 118 \& practical 191 bus test systems and simulation results show clearly the superior performance of the proposed Wide-ranging vicinity Algorithm (WVA) in reducing the real power loss \& voltage profiles are within the limits.

\section{Problem Formulation}

\subsection{Active Power Loss}

The objective of the reactive power problem is to minimize the active power loss in the transmission network, which can be described as follows:

$F=P L=\sum_{k \in N b r} g_{k}\left(V_{i}^{2}+V_{j}^{2}-2 V_{i} V_{j} \cos \theta_{i j}\right)$

$F=P L=\sum_{i \in N g} P_{g i}-P_{d}=P_{g s l a c k}+\sum_{i \neq s l a c k}^{N g} \stackrel{\text { Or }}{ } P_{g i}-P_{d}$

Where $g_{k}$ : is the conductance of branch between nodes $i$ and $j$, Nbr: is the total number of transmission lines in power systems. $\mathrm{P}_{\mathrm{d}}$ : is the total active power demand, $\mathrm{P}_{\mathrm{gi}}$ : is the generator active power of unit $i$, and $\mathrm{P}_{\text {gsalck: }}$ is the generator active power of slack bus.

\subsection{Voltage Profile Improvement}

For minimizing the voltage deviation in PQ buses, the objective function becomes:

$F=P L+\omega_{v} \times V D$

Where $\omega_{\mathrm{v}}$ : is a weighting factor of voltage deviation.

VD is the voltage deviation given by: 
$V D=\sum_{i=1}^{N p q}\left|V_{i}-1\right|$

\subsection{Equality Constraint}

The equality constraint of the problem is represented by the power balance equation, where the total power generation must cover the total power demand and the power losses,

$P_{G}=P_{D}+P_{L}$

This equation is solved by running Newton Raphson load flow method, by calculating the active power of slack bus to determine active power loss.

\subsection{Inequality Constraints}

The inequality constraints reflect the limits on components in the power system as well as the limits created to ensure system security. Upper and lower bounds on the active power of slack bus, and reactive power of generators:

$P_{\text {gslack }}^{\min } \leq P_{\text {gslack }} \leq P_{\text {gslack }}^{\max }$

$Q_{g i}^{\min } \leq Q_{g i} \leq Q_{g i}^{\max }, i \in N_{g}$

Upper and lower bounds on the bus voltage magnitudes:

$V_{i}^{\min } \leq V_{i} \leq V_{i}^{\max }, i \in N$

Upper and lower bounds on the transformers tap ratios:

$T_{i}^{\text {min }} \leq T_{i} \leq T_{i}^{\max }, i \in N_{T}$

Upper and lower bounds on the compensators reactive powers:

$Q_{c}^{\min } \leq Q_{c} \leq Q_{C}^{\max }, i \in N_{C}$

Where $\mathrm{N}$ is the total number of buses, $\mathrm{N}_{\mathrm{T}}$ is the total number of Transformers; $\mathrm{N}_{\mathrm{c}}$ is the total number of shunt reactive compensators.

\section{Wide-Ranging Vicinity Algorithm (WVA)}

The proposed Wide-ranging vicinity Algorithm (WVA) will work to discover the optimal value among the local optima by switching between exploration and exploitation. Exploration permits for exploring the whole search space. Exploitation permits focusing the search in the neighbourhood of the best solution of produced solutions.

The objective function we assume to explain the methodology is, 
$\min g=f\left(x_{1}, x_{2}, \ldots, x_{n}\right)$

Where,

$x_{1}, x_{2}, \ldots, x_{n}$, are the different combinations of the solution sequence.

We need to discover the optimal combination or solution $\left(X_{1}, X_{2}, \ldots, X_{n}\right)$ that will give the optimal (minimum) value for the objective function .In general, if each of the variables $\left(X_{1}, X_{2}, \ldots, X_{n}\right)$ can be chosen in $\left(n_{1}, n_{2}, \ldots, n_{n}\right)$ ways respectively, then if we want to enumerate all the possible solutions this will yield $\left(n_{1}, n_{2}, \ldots, n_{n}\right)$ solutions [21,22].

According to the Wide-ranging vicinity Algorithm (WVA), set of (m) arbitrary solutions are first arbitrarily generated from the set of all possible solution, where, $\left(X_{1}, X_{2}, \ldots, X_{n}\right)$ can be chosen $\operatorname{in}\left(n_{1}, n_{2}, \ldots, n_{n}\right)$ ways. The generated solutions will then appear as: $\left(X_{1}^{q}, X_{2}^{q}, \ldots, X_{n}^{q}\right)$ where $q=$ $1,2, \ldots, m$.

The fitness for the above solution will be calculated and it can be done by substituting them in the objective function. The solutions are then classified according to their fitness obtained from the objective function.

$f\left(s_{1}\right)<f\left(s_{2}\right)<f\left(s_{3}\right)<\cdots<f\left(s_{m}\right)$

$s_{1}=\left(X_{1}^{\prime}, X_{2}^{\prime}, \ldots, X_{n}^{\prime}\right)$ is the solution sequence with best fitness. The most excellent amalgamation $\left(s_{1}\right)$ is then used as a high-quality measure for the local optimal solution and it is also primarily set as the finest known solution. In the next iteration, $50 \%$ of the $(\mathrm{m})$ produced solutions will be generated near the most excellent solution neighborhood by using a appropriate move operator. The other $50 \%$ of the $(\mathrm{m})$ generated solutions will be still produced from the whole explore space, and the cause for that is to permit for the exploration of the search space, because if we just prefer the solutions close to the most excellent solution and we can find the local solution in the region of this point, and since the function that need to be optimized might have more than one local optima, which might guide us to get jammed at one of these local optima. Next, the best solution from the above $(\mathrm{m})$ solutions $(50 \%, 50 \%)$ is computed. The fresh value for the best solution is compared to best known solution and if it was found to be superior it will replace it. The process is then repeated until a certain end criterion is met. This end criterion can be a pre-specified number of iterations ( $\mathrm{t}$ ), or when there is no further enhancement on the final value of the optimal solution we obtained.

Wide-ranging vicinity Algorithm (WVA) for solving optimal reactive power problem
a. Start
b. Define objective function, variables and WVA parameters
c. Produce $(\mathrm{m})$ feasible solutions from the entire explore space.
d. Using the objective function compute the fitness function for all produced (m) solutions.
e. Optimal solution $(\mathrm{OS})=$ fittest solution (most excellent solution)
f. $I=0$
g. Produce $(50 \% \times \mathrm{m})$ solutions from the neighbourhood of the fittest solution (most excellent) using a suitable move operator.
h. Produce $(50 \% \times m)$ solutions from the entire search space. 
i. Find the fittest solution (most excellent) from above produced (m) solutions.

j. Is most excellent solutions (better than) optimal solution (OS)?

$\mathrm{k}$. If yes, then $\mathrm{OS}=$ most excellent solution

1. If no, $\mathrm{I}=\mathrm{I}+1$

m. Is $\mathrm{I}<\mathrm{t}$ ?

n. If yes, then go to step g

o. Or else stop.

Portray objective function

Initialize the values for all parameters: $\mathrm{m}, \mathrm{t}$

Generate $(\mathrm{m})$ feasible solutions from the exploration space

Compute the fitness from the objective function

Optimal solution $=$ the most excellent solution.

$\mathrm{i}=1$

Do while $\mathrm{I}<\mathrm{t},++$

Generate $50 \% \times \mathrm{m}$ solutions from the vicinity of the most excellent solution

Generate $50 \% \times \mathrm{m}$ solutions from the explore space

Find out the most excellent solution from the $(\mathrm{m})$ formed solution

If most excellent solution is less (better) than optimal solution

Optimal solution=most excellent solution

End If

End DO

\section{Simulation Results}

At first Wide-ranging vicinity Algorithm (WVA) has been tested in standard IEEE 118-bus test system [23].The system has 54 generator buses, 64 load buses, 186 branches and 9 of them are with the tap setting transformers. The limits of voltage on generator buses are $0.95-1.1$ per-unit., and on load buses are $0.95-1.05$ per-unit. The limit of transformer rate is $0.9-1.1$, with the changes step of 0.025 . The limitations of reactive power source are listed in Table 1 , with the change in step of 0.01 .

Table 1: Limitation of reactive power sources

\begin{tabular}{|l|l|l|l|l|l|l|l|}
\hline BUS & 5 & 34 & 37 & 44 & 45 & 46 & 48 \\
\hline QCMAX & 0 & 14 & 0 & 10 & 10 & 10 & 15 \\
\hline QCMIN & -40 & 0 & -25 & 0 & 0 & 0 & 0 \\
\hline BUS & 74 & 79 & 82 & 83 & 105 & 107 & 110 \\
\hline QCMAX & 12 & 20 & 20 & 10 & 20 & 6 & 6 \\
\hline QCMIN & 0 & 0 & 0 & 0 & 0 & 0 & 0 \\
\hline
\end{tabular}

The statistical comparison results of 50 trial runs have been list in Table 2 and the results clearly show the better performance of proposed Wide-ranging vicinity Algorithm (WVA) approach. 
Table 2: Comparison results

\begin{tabular}{|l|l|l|l|l|}
\hline Active power loss (p.u) & $\begin{array}{l}\text { BBO } \\
{[\mathbf{2 4}]}\end{array}$ & $\begin{array}{l}\text { ILSBBO/ } \\
\text { strategy1 } \\
{[\mathbf{2 4}]}\end{array}$ & $\begin{array}{l}\text { ILSBBO/ } \\
\text { strategy1 } \\
{[\mathbf{2 4}]}\end{array}$ & $\begin{array}{l}\text { Proposed } \\
\text { WVA }\end{array}$ \\
\hline Min & 128.77 & 126.98 & 124.78 & 117.48 \\
\hline Max & 132.64 & 137.34 & 132.39 & 122.96 \\
\hline Average & 130.21 & 130.37 & 129.22 & 119.52 \\
\hline
\end{tabular}

Then the Wide-ranging vicinity Algorithm (WVA) has been tested in practical 191 test system and the following results have been obtained. In Practical 191 test bus system - Number of Generators $=20$, Number of lines $=200$, Number of buses $=191$ Number of transmission lines $=$ 55. Table 3 shows the optimal control values of practical 191 test system obtained by WVA method. And table 4 shows the results about the value of the real power loss by obtained by Wide-ranging vicinity Algorithm (WVA).

Table 3: Optimal Control values of Practical 191 utility (Indian) system by WVA method

\begin{tabular}{l|l|l|l|l}
\hline VG1 & 1.100 & & VG 11 & 0.900 \\
\hline VG 2 & 0.780 & VG 12 & 1.000 \\
\hline VG 3 & 1.010 & VG 13 & 1.000 \\
\hline VG 4 & 1.010 & VG 14 & 0.900 \\
\hline VG 5 & 1.100 & VG 15 & 1.000 \\
\hline VG 6 & 1.100 & VG 16 & 1.000 \\
\hline VG 7 & 1.100 & VG 17 & 0.900 \\
\hline VG 8 & 1.010 & VG 18 & 1.000 \\
\hline VG 9 & 1.100 & VG 19 & 1.100 \\
\hline VG 10 & 1.010 & VG 20 & 1.100 \\
\hline
\end{tabular}

\begin{tabular}{|c|c|c|c|c|c|}
\hline $\mathrm{T} 1$ & 1.000 & $\mathrm{~T} 21$ & 0.900 & T41 & 0.900 \\
\hline $\mathrm{T} 2$ & 1.000 & $\mathrm{~T} 22$ & 0.900 & $\mathrm{~T} 42$ & 0.900 \\
\hline T3 & 1.000 & $\mathrm{~T} 23$ & 0.900 & T43 & 0.910 \\
\hline $\mathrm{T} 4$ & 1.100 & $\mathrm{~T} 24$ & 0.900 & T44 & 0.910 \\
\hline T5 & 1.000 & $\mathrm{~T} 25$ & 0.900 & T45 & 0.910 \\
\hline T6 & 1.000 & T26 & 1.000 & T46 & 0.900 \\
\hline $\mathrm{T} 7$ & 1.000 & $\mathrm{~T} 27$ & 0.900 & T47 & 0.910 \\
\hline $\mathrm{T} 8$ & 1.010 & $\mathrm{~T} 28$ & 0.900 & T48 & 1.000 \\
\hline T9 & 1.000 & $\mathrm{~T} 29$ & 1.010 & T49 & 0.900 \\
\hline T10 & 1.000 & T30 & 0.900 & T50 & 0.900 \\
\hline T11 & 0.900 & T31 & 0.900 & T51 & 0.900 \\
\hline T12 & 1.000 & $\mathrm{~T} 32$ & 0.900 & T52 & 0.900 \\
\hline $\mathrm{T} 13$ & 1.010 & T33 & 1.010 & T53 & 1.000 \\
\hline T14 & 1.010 & T34 & 0.900 & T54 & 0.900 \\
\hline T15 & 1.010 & T35 & 0.900 & T55 & 0.900 \\
\hline T19 & 1.020 & T39 & 0.900 & & \\
\hline T20 & 1.010 & $\mathrm{~T} 40$ & 0.900 & & \\
\hline
\end{tabular}


Table 4: Optimum real power loss values obtained for practical 191 utility (Indian) system by WVA method.

\begin{tabular}{l|l}
\hline $\begin{array}{l}\text { Real power Loss } \\
(\mathrm{MW})\end{array}$ & WVA \\
\hline Min & 146.184 \\
\hline Max & 149.128 \\
\hline Average & 147.006 \\
\hline
\end{tabular}

\section{Conclusion}

Wide-ranging vicinity Algorithm (WVA) algorithm has been successfully applied to solve optimal reactive power problem. Wide-ranging vicinity Algorithm equally improves the local \& global search. From the global search space a set of arbitrary solutions are primarily generated and then the most excellent solution given the optimal value. The proposed Wide-ranging vicinity Algorithm (WVA) has been tested on standard IEEE 118 \& practical 191 bus test systems and simulation results show clearly the superior performance of the proposed Wideranging vicinity Algorithm (WVA) in reducing the real power loss \& voltage profiles are within the limits.

\section{References}

[1] O. Alsac, B. Scott, "Optimal load flow with steady state security", IEEE Transaction. PAS -1973, pp. 745-751.

[2] Lee K Y ,Paru Y M , Oritz J L -A united approach to optimal real and reactive power dispatch , IEEE Transactions on power Apparatus and systems 1985: PAS-104 : 1147-1153

[3] A. Monticelli , M .V.F Pereira, and S. Granville, "Security constrained optimal power flow with post contingency corrective rescheduling", IEEE Transactions on Power Systems :PWRS-2, No. 1, pp.175-182.,1987.

[4] Deeb N, Shahidehpur S.M, Linear reactive power optimization in a large power network using the decomposition approach. IEEE Transactions on power system 1990: 5(2) : 428-435

[5] E. Hobson ,'Network cons rained reactive power control using linear programming, ' IEEE Transactions on power systems PAS -99 (4),pp 868=877, 1980

[6] K.Y Lee, Y.M Park, and J.L Oritz, "Fuel -cost optimization for both real and reactive power dispatches", IEE Proc; 131C, (3), pp.85-93.

[7] M.K. Mangoli, and K.Y. Lee, "Optimal real and reactive power control using linear programming", Electr.Power Syst.Res, Vol.26, pp.1-10,1993.

[8] C.A. Canizares, A.C.Z.de Souza and V.H. Quintana, "Comparison of performance indices for detection of proximity to voltage collapse," vol. 11. no.3, pp.1441-1450, Aug 1996.

[9] K.Anburaja, "Optimal power flow using refined genetic algorithm", Electric Power Compon.Syst , Vol. 30, 1055-1063,2002.

[10] D. Devaraj, and B. Yeganarayana, "Genetic algorithm based optimal power flow for security enhancement", IEE proc-Generation.Transmission and. Distribution; 152, 6 November 2005.

[11] A Berizzi, C. Bovo, M. Merlo, and M. Delfanti, "A ga approach to compare or pf objective functions including secondary voltage regulation, "Electric Power Systems Research, vol. 84, no. 1, pp. $187-194,2012$.

[12] C.-F. Yang, G. G. Lai, C.-H. Lee, C.-T. Su, and G. W. Chang, "Optimal setting of reactive compensation devices with an improved voltage stability index for voltage stability 
enhancement," International Journal of Electrical Power and Energy Systems, vol. 37, no. 1, pp. $50-57,2012$.

[13] P. Roy, S. Ghoshal, and S. Thakur, "Optimal var control for improvements in voltage profiles and for real power loss minimization using biogeography based optimization," International Journal of Electrical Power and Energy Systems, vol. 43, no. 1, pp. 830 - 838, 2012.

[14] B. Venkatesh, G. Sadasivam, and M. Khan, "A new optimal reactive power scheduling method for loss minimization and voltage stability margin maximization using successive multi-objective fuzzy lp technique ,'IEEE Transactions on Power Systems, vol. 15, no. 2, pp. 844 -851, may 2000.

[15] W. Yan, S. Lu, and D. Yu, "A novel optimal reactive power dispatch method based on an improved hybrid evolutionary programming technique ,"IEEE Transactions on Power Systems, vol. 19, no. 2, pp. $913-918$, may 2004.

[16] W. Yan, F. Liu, C. Chung, and K. Wong, "A hybrid genetic algorithm interior point method for optimal reactive power flow," IEEE Transactions on Power Systems, vol. 21, no. 3, pp. 1163 1169, aug. 2006.

[17] J. Yu, W. Yan, W. Li, C. Chung, and K. Wong, "An unfixed piece wise optimal reactive powerflow model and its algorithm for ac-dc systems ,"IEEE Transactions on Power Systems, vol. 23, no. 1, pp. $170-176$, feb.2008.

[18] F. Capitanescu, "Assessing reactive power reserves with respect to operating constraints and voltage stability," IEEE Transactions on Power Systems, vol. 26, no. 4, pp. 2224-2234, Nov. 2011.

[19] Z. Hu, X. Wang, and G. Taylor, "Stochastic optimal reactive power dispatch: Formulation and solution method," International Journal ofElectrical Power and Energy Systems, vol. 32, no. 6, pp. $615-621,2010$.

[20] A Kargarian, M. Raoofat, and M. Mohammadi, "Probabilistic reactive power procurement in hybrid electricity markets with uncertain loads ,"Electric Power Systems Research, vol. 82, no. 1, pp. $68-80,2012$.

[21] T. Weise, Global Optimization Algorithms - Theory and Application, Germany: it-weise.de (selfpublished), [Online]. Available: http://www.it-weise.de/, 2009.

[22] Azmi Alazzam and Harold W. Lewis III- A New Optimization Algorithm for Combinatorial Problems, International Journal of Advanced Research in Artificial Intelligence, Vol. 2, No.5, 2013.

[23] IEEE, "The IEEE 30-bus test system and the IEEE 118-test system", (1993), http://www.ee.washington.edu/trsearch/pstca/.

[24] Jiangtao Cao, Fuli Wang and Ping Li, "An Improved Biogeography-based Optimization Algorithm for Optimal Reactive Power Flow", International Journal of Control and Automation Vol.7, No.3 (2014), pp.161-176.

\footnotetext{
*Corresponding author.

E-mail address: gklenin@gmail.com
} 